\title{
Indicadores Ambientais Relevantes para a Análise da Suscetibilidade à Erosão dos Solos em Açailândia (MA).
}

\author{
Mônica dos Santos Marçal $^{1} \&$ Antonio José Teixeira Guerra ${ }^{1}$ \\ ${ }^{1}$ LAGESOLOS Laboratório de Geomorfologia Ambiental e Degradação dos Solos/UFRJ \\ Depto de Geografia. Ilha do Fundão, Cidade Universitária, CEP 21940-590, Rio de Janeiro. \\ Telefone: (21) 25511537-monicamarcal@uol.com.br
}

\begin{abstract}
Resumo
Este artigo trata do papel das características do relevo, tipos de solos, uso da terra e cobertura vegetal, com o objetivo de estimar os riscos de erosão, usando geoprocessamento. Aárea de estudo é a bacia do rio Açailândia, com $1009 \mathrm{Km}^{2}$, no estado do Maranhão. Os resultados mostram três principais áreas suscetíveis à erosão: pouco suscetível, suscetível e crítica, levando em conta uma combinação de associação de solos, uso da terra, cobertura vegetal e características do relevo.
\end{abstract}

Palavras chave: erosão dos solos, suscetibilidade erosiva, geoprocessamento

\begin{abstract}
This paper regards the role of relief characteristics, soil type, land use and vegetation cover, in order to assess soil erosion risk, using geoprocessing. The study area is Açailândia drainage basin, with $1009 \mathrm{Km}^{2}$, in Maranhão State. The results show three main areas susceptible to erosion: low, medium and high risk, taking into account a combination of soil association, land use, vegetation cover and relief characteristics.
\end{abstract}

Key words: soil erosion, environmental risk, geoprocessing

\section{Introdução}

Na Amazônia Legal, a transformação da floresta em agrossistema ainda se encontra em franco desenvolvimento e tem se limitado, na maioria das vezes, à derrubada da mata, queima e plantio, geralmente não levando em consideração as formas de relevo e cursos d'água.

Açailândia, município no estado do Maranhão, surgiu na década de 60 , em função da construção da rodovia BR-010; possui uma população de 102.609 habitantes (IBGE, 1996), e, nas duas últimas décadas, tem sido alvo dos mais diversos interesses econômicos. Possui uma localização estratégica (Figura 1), no entroncamento rodoferroviário, formado pelas rodovias Belém-Brasília (BR-.010) e BR-222, que liga a Belém/Brasília à BR316 (Pará/Maranhão), onde se formou ainda o entroncamento das ferrovias Carajás - São Luís e Norte-Sul (primeiro trecho), ligando Açailândia à cidade Imperatriz situada $80 \mathrm{Km}$ ao sul. 

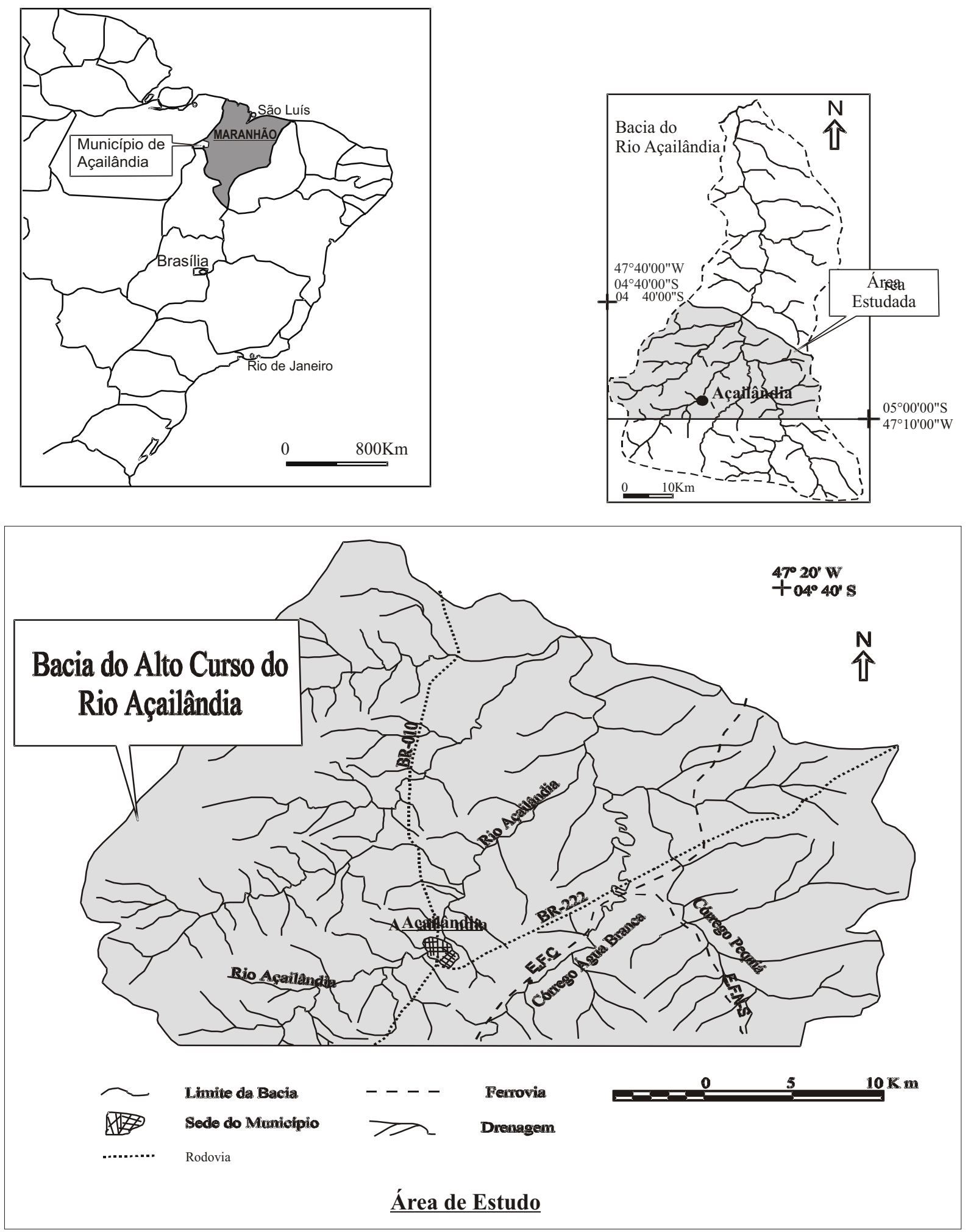

Figura 1. Localização da área de estudo, no Município de Açailândia

No contexto do Programa Grande Carajás (PGC), criou-se em Açailândia um polo industrial que se destaca no estado, com indústrias madeireiras (nos seus diversos segmentos), siderúrgicas e ainda um comércio significativo.

O desmatamento de extensas áreas, sem manejo adequado vem causando um intenso processo de degradação nos solos, principalmente na área considerada de maior índice de ocupação humana do município, a bacia do rio Açailândia. A área selecionada para estudo se encontra na porção central do município, com $1.009 \mathrm{Km}^{2}$ do total dos $2.401 \mathrm{Km}^{2}$ correspondentes à bacia, e foi denominada de alto curso da bacia do rio Açailândia. Ressalta-se que esta área corresponde a uma das regiões mais afetadas pela erosão (Marçal, 2000). 
Este trabalho apresenta uma análise da suscetibilidade à erosão dos solos no alto curso da bacia do rio Açailândia, levando-se em conta as características do relevo, do solo e do uso da terra nas duas últimas décadas.

\section{Metodologia}

Realizou-se a análise ambiental da área considerando, além dos condicionantes físicos (solo, relevo, geologia, drenagem, declividade, clima e feições erosivas), as interações entre os elementos geográficos tais como localização, posição, mapeamento do uso da terra, formas de urbanização e atividades econômicas da área de estudo. Estas interações são reproduzidas sob a forma de cruzamento de planos de informações, com base em técnicas de geoprocessamento, onde foram elaborados mapas temáticos georreferenciados.

Com uma visão regional, procurou-se explicar a ocorrência dos processos erosivos que se apresentam nas áreas urbanas e rurais do município de Açailândia, através das relações que se estabelecem entre os fatores solo, geomorfologia, declividade e uso do solo, tanto a nível regional quanto local.

Para esse estudo utilizou-se técnica de geoprocessamento - o Sistema de Informação Geográfica e Sensoriamento Remoto - importantes na aquisição, manipulação e interpretação de dados temáticos, oferecendo subsídios para a correlação dos processos erosivos com os condicionantes físicos e a caracterização das áreas suscetíveis à erosão.

Os trabalhos envolveram atividades de campo, laboratório e gabinete. Os trabalhos de campo compreenderam a identificação das feições erosivas e o levantamento das unidades estudadas, com descrição e coleta de amostras. As formas erosivas e os pontos de identificação foram devidamente localizados e plotados na base cartográfica (Guerra et al., 1998; Marçal, 2000).

O mapeamento das formas erosivas (erosão laminar, ravinas e voçorocas) foi realizado ao longo das duas rodovias que cortam a área da bacia do rio Açailândia, a BR-010 e BR-222, e em áreas próximas a elas. Entende-se por voçoroca, nesse trabalho, as feições erosivas com pelo menos $0,5 \mathrm{~m}$ de largura, $0,5 \mathrm{~m}$ de profundidade e $30 \mathrm{~m}$ de comprimento (Glossary of Soil Science Terms, 1987).

As observações de campo para a descrição morfológica dos solos foram realizadas em cerca de 50 pontos de identificação, dos quais 30 foram acompanhados de preenchimento de ficha de descrição da unidade de mapeamento. Para o estudo do relevo e geologia os trabalhos de campo compreenderam o reconhecimento, identificação e mapeamento das unidades fotointerpretadas (Marçal, 2000).

Os trabalhos de laboratório envolveram análises morfológicas, físicas, químicas e mineralógicas de amostras de solo e foram encaminhadas ao Laboratório de Pedologia da Universidade Federal do
Rio de Janeiro (UFRJ) e EMBRAPA-CNPS (RJ). As determinações morfológicas realizadas compreenderam cor, utilizando a carta de Münsell (1975) e nomes correspondentes em português; estrutura, com relação à forma e tamanho; consistência, em amostra seca, úmida e molhada; e raízes, fazendo a determinação com relação à quantidade.

As amostras de solo foram pesadas, destorroadas e passadas em peneira de 2,0 $\mathrm{mm}$ de diâmetro de malha, para se realizar a separação das frações calhau e cascalho da fração terra fina seca ao ar (TFSA). A partir daí, as análises realizadas foram: granulometria, densidade aparente e real.

As determinações químicas foram realizadas no Laboratório de Pedologia da Universidade Federal do Rio de Janeiro (UFRJ), sendo que, as análises de ataque por $\mathrm{H}_{2} \mathrm{SO}_{4}$ foram realizadas pela EMBRAPA/CNPS (RJ). As seguintes determinações foram realizadas: teor de matéria orgânica e carbono orgânico, pH, $\mathrm{SiO}_{2} \mathrm{AlO}_{{ }_{3}} \mathrm{FeO}_{2}, \mathrm{TiO}_{3} \mathrm{Ki}$ e Kr.

As determinações mineralógicas foram realizadas a partir da fração argila, por difratometria de raios-X, de amostras de horizontes subsuperficiais, dos perfis representativos dos tipos de solo identificados na área. Tais análises foram executadas pela EMBRAPA/CNPS (RJ).

Os trabalhos de gabinete corresponderam à revisão bibliográfica e análise crítica dos conhecimentos sobre a área de estudo, envolvendo temas relacionados a processos erosivos, análise e impacto ambiental, levantamento de material de apoio disponíveis nas instituições, incluindo livros, mapas, fotografias aéreas, imagens de satélites e radar, e análise e revisão bibliográfico-cartográfica referente à área em questão, destacando-se estudos de solo, relevo e geologia, realizados pelo RADAMBRASIL (Brasil, 1973) e EMBRAPA (1986).

Nesta etapa foram realizados os levantamentos básicos de caracterização morfométrica da bacia de drenagem do rio Açailândia e sua base cartográfica, com o auxílio da carta planialtimétrica (IBGE/DSG, 1984) na escala de 1:100.000 das folhas: SB23-V.A-IV (Açailândia), SB23-V.A-V (Açailândia-E), SA23-V.A-II (Guaramandi), SB23V.C-I (Cidelândia), SB23-V.C-II (João Lisboa). Posteriormente, foram realizadas interpretação visual das imagens de satélite Landsat TM/5 de 1991 e 1996, composição colorida das bandas 3B 4G e 5R, órbita/ ponto $(222 / 63$ e 222/64) na escala de $1: 100.000$, e das fotografias aéreas na escala 1:100.000 da CPRM, ano de 1980.

Os mapeamentos e as informações obtidas em campo foram integrados a partir de mapas temáticos: solo, relevo e feições erosivas, drenagem, declividade e hipsometria (Marçal e Correa, 1995; Garcia et al., 1998; Marçal, 2000). Os mapeamentos sobre usos da terra nos anos de 1985, 1991 e 1996 foram realizados através das imagens de satélite Landsat, o que possibilitou a análise temporal e a quantificação das transformações ocorridas com 
relação ao desmatamento na região (Marçal, 2000).

O mapeamento dos solos foi elaborado com

base nas normas estabelecidas pelo Centro Nacional de Pesquisas de Solos (EMBRAPA, 1995). A partir da interpretação das imagens de satélite e fotografias aéreas (escala 1:100.000) e dos trabalhos de campo para abertura de perfis e realização de tradagens, foram identificadas as classes de solo e suas áreas de abrangência. A legenda final foi elaborada com base nos resultados das análises laboratoriais, já enquadradas no novo Sistema Brasileiro de Classificação de Solos (EMBRAPA, 1999).

Foram identificadas cinco classes de solo, sendo que apenas duas foram mapeadas na escala do trabalho. Intergrades entre essas duas classes mapeadas foram individualizadas e separadas, compondo uma legenda final com associações entre as unidades. Ressalta-se que as associações se devem pelo fato da dificuldade em individualizar as classes de solos identificadas como intergrades na escala apresentada no trabalho.

A compartimentação geomorfológica do alto curso da bacia do rio Açailândia foi baseada nas informações do mapeamento e interpretação das feições geomorfológicas realizadas para o município de Açailândia, por Marçal e Corrêa (1995). Os trabalhos foram baseados na metodologia utilizada pelo Projeto RADAMBRASIL (Brasil, 1990).

O mapa de declividade foi realizado com base nas cartas topográficas referentes às folhas Açailândia e Açailândia-E, ambas na escala de 1:100.000 (Garcia et al., 1998). As classes de declive usadas neste mapeamento foram adaptadas do Centro Nacional de Pesquisas de Solos (EMBRAPA/CNPS1995), a fim de atender adequadamente à caracterização do ambiente estudado.

Baseando-se na metodologia de De Biasi (1970) e contribuições de Sanchez (1993), foi feita a construção dos ábacos. Para o uso dos ábacos foram consideradas as eqüidistâncias entre as curvas de nível de 50 metros, de acordo com as cartas topográficas utilizadas. Foram definidas as seguintes classes, de acordo com o relevo correspondente: 0-3\% (plano), 3$8 \%$ (suave ondulado), $8-12 \%$ (moderadamente ondulado), $12-20 \%$ (ondulado), $20-30 \%$ (forte ondulado), $30-45 \%$ (forte ondulado), e maior do que $45 \%$ (montanhoso).

O levantamento detalhado da rede hidrográfica da área, foi realizado através da fotointerpretação das imagens de satélite Landsat, na escala de 1:100.000, e das fotografias aéreas também em escala de 1:100.000. Com base na rede hidrográfica detalhada, pode-se caracterizar o padrão de drenagem do tipo dendrítico, correlacionando com os aspectos regionais da área de estudo. Foi possível individualizar dois domínios desse padrão de drenagem que se diferenciam pela sua densidade de drenagem. O primeiro com densidade maior, localiza-se nos extremos oeste e leste da área de estudo, e o segundo com densidade menor, na área central da área de estudo. Neste último, os rios apresentam-se com formas mais alongadas e com um alinhamento de drenagem direcionado para NW-SE.

Os estudos sobre o levantamento do uso da terra foram obtidos mediante a interpretação visual de imagens de satélites Landsat TM/5, composição preto e branco nas bandas 4 e 5 , para o ano de 1985; e de composição colorida nas bandas 3B, 4G e 5R, para os anos de 1991 e 1996. Algumas observações foram realizadas durante os trabalhos de campo.

Para a interpretação visual das imagens de satélite, foram utilizados os parâmetros interpretativos de cor. Para a definição da legenda, foram considerados todos os tipos de ocupação antrópica (pasto, agricultura e área com queimada), como área agropastoril. As áreas onde a floresta permanece nativa e secundária foram consideradas áreas com vegetação. O núcleo urbano e a área industrial foram considerados como classe à parte.

A técnica do geoprocessamento envolveu a conversão dos mapas analógicos para o formato digital, onde os mesmos foram rasterizados, georreferenciados e vetorizados, para posterior realização das funções de cruzamento entre imagens, vetores e análises multitemporais.

Os cruzamentos, ou integração dos dados, envolveram as informações básicas de relevo, solo e uso da terra, visando a produção de um mapa de avaliação que hierarquizasse as áreas potenciais para ocorrência de erosão. Foram efetuados dois cruzamentos entre os planos de informação e dados de campo.

A partir de informações de campo e fotointerpretação foi produzido um mapa de localização de feições erosivas, o que possibilitou a confirmação dos cruzamentos produzidos. A integração do mapa de feições erosivas com os cruzamentos permitiu a visualização do predomínio da localização das voçorocas em relação às novas classes, possibilitando a hierarquização de áreas suscetíveis e explicação para a sua ocorrência (Marçal, 2000). Foram resgatados os resultados granulométricos de quatro monitoramentos de voçorocas realizados em trabalho anterior (Marçal, 2000) com o fim de mostrar as diferenças em relação aos solos.

\section{Fatores Ambientais Relevantes}

\section{dos solos}

\section{1-As formas de relevo e as características}

A compartimentação geomorfológica do município de Açailândia foi realizada por Marçal e Corrêa (1995) na escala de 1:100.000, onde foi possível identificar três superfícies de aplainamento que se apresentam em níveis topográficos distintos e inclinados em direção aos vales dos rios principais. Segundo Brasil (1990) a primeira, mais antiga, é chamada de superfície de cimeira $\mathbf{P d} \mathbf{3}$ em torno de 300-380m; e em ordem decrescente de idade tem-se a 
segunda, Pd2, em torno de 200m; e a terceira, Pd1, abaixo de $100 \mathrm{~m}$. Foram também identificadas diferentes fácies de dissecação do relevo, de acordo com o grau de dissecação.

Com o levantamento realizado, constatou-se que a bacia do rio Açailândia, localizada no centro do município, encontra-se posicionada entre os contrafortes do Planalto do Tiracambu (que corresponde à superfície de aplainamento Pd3), mais precisamente em área de relevo dissecado (Marçal e Côrrea, 1995). Dessa forma, no alto curso da bacia do rio Açailândia, que possui uma área de aproxima-damente $1.009 \mathrm{Km}^{2}$, foram identificados três níveis de dissecação do relevo, compartimentados em níveis topográficos distintos, inclinados em direção ao vale do rio principal, denominadas de Fácies 1, 2 e 3 (F1, F2 e F3).

O relevo em forma de dissecação F1 (330,72

$\mathrm{Km}^{2}$ ) corresponde aos altos cursos dos rios, apresentando uma vasta rede de drenagem com rios de pequena extensão, caracterizando-se por apresentar intensa cobertura vegetal, topo agudo com altitudes entre 200 e $250 \mathrm{~m}$ e baixa atividade antrópica. Apresenta índice de dissecação que varia de $250 \mathrm{~m}$ a $750 \mathrm{~m}$, com forte grau de intensidade de aprofundamento da drenagem. Compreendem as áreas com as maiores inclinações das vertentes, entre 12 e $20 \%$ $\left(45,89 \mathrm{~km}^{2}\right), 20$ e $30 \%\left(19,08 \mathrm{~km}^{2}\right), 30$ e $45 \%(16,26$ $\left.\mathrm{km}^{2}\right)$ e superior a $45 \%\left(8,48 \mathrm{~km}^{2}\right)$.

O relevo em forma de dissecação F2 (180,8 $\mathrm{km}^{2}$ ), que corresponde aos médios cursos dos rios, caracteriza-se por apresentar uma fraca densidade, com rios de média extensão e uma menor densidade de cobertura vegetal, topos convexos com altitudes que variam de 150 a $200 \mathrm{~m}$, com intensa atividade antrópica, apresentando um índice de dissecação que varia de $1.750 \mathrm{~m}$ a $3.750 \mathrm{~m}$, com fraco grau de intensidade de aprofundamento da drenagem. São áreas que apresentam uma declividade mais suave, que varia entre 12 e $20 \%\left(45.89 \mathrm{~km}^{2}\right), 8$ e $12 \%(196,84$ $\left.\mathrm{km}^{2}\right), 3$ e $8 \%\left(151,00 \mathrm{~km}^{2}\right)$ e 0 e $3 \%\left(538,44 \mathrm{~km}^{2}\right)$.

O relevo em forma de dissecação F3 (373,12 $\mathrm{km}^{2}$ ), que corresponde aos baixos cursos dos rios, apresenta uma fraca densidade, com rios de grande extensão, onde os leitos dos mesmos apresentam-se mais alongados e com poucos afluentes e ausência quase total de cobertura vegetal. Apresenta topos convexos com altitudes abaixo de $150 \mathrm{~m}$, com intensa atividade antrópica. $\mathrm{O}$ índice de dissecação varia de $1.750 \mathrm{~m}$ a $12.750 \mathrm{~m}$, com grau de intensidade de aprofundamento da drenagem mais fraco que o anterior. São áreas que apresentam as menores inclinações das vertentes, 0 e $3 \%\left(538,44 \mathrm{~km}^{2}\right)$ e 3 e $8 \%\left(151 \mathrm{~km}^{2}\right)$.

As superfícies aplainadas e mais elevadas Pd3 (124,99 km²), são constituídas de topos planos a suavemente ondulados. Nestas áreas, a dissecação é incipiente, pois as condições de drenagem dos solos são boas, e a ocupação antrópica e o desmatamento são baixos, quando comparados com as outras áreas. Esta superfície corresponde à Serra do Tiracambu que limita a leste-oeste a bacia do rio Açailândia, entre colinas que se caracterizam pela fácies de dissecação identificada na área.

Com relação à distribuição do solo no alto curso da bacia do rio Açailândia, observa-se que nas áreas mais elevadas e de superfície suave, a presença do Latossolo Vermelho-Amarelo (LV1) é mais freqüente. São áreas que apresentam altitudes em torno de 200 a 250 metros e estão localizadas nas regiões de limite leste e oeste da área estudada, correspondendo às superfícies aplainadas e mais elevadas (Planalto do Tiracambu). Proporcionalmente, correspondem a áreas com menor índice de desmatamento, apresentando baixa atividade antrópica, havendo alguma erosão laminar, em ravinas e em voçorocas, nas áreas com menor quantidade de cobertura vegetal.

Nas encostas dessas áreas mais elevadas, em geral, ocorre a associação do Argissolo VermelhoAmarelo, Argissolo Vermelho-Amarelo latossólico, Argissolo Amarelo e Argissolo Amarelo latossólico (P). São áreas com altitudes em torno de 150 a 200 metros, com encostas colinosas, estando distribuídas em faixas laterais à superfície anterior. Apesar de apresentarem um índice de desmatamento elevado, correspondem proporcionalmente, às áreas menos ocupadas e com maior densidade de vegetação. Nestas áreas há a ocorrência com menor intensidade de voçorocas e ravinas, sendo mais freqüente a erosão laminar, o que foi constatado nos trabalhos de campo (Marçal, 2000).

Nas áreas mais baixas, que correspondem às partes centrais da bacia, ocorre a associação de Latossolo Vermelho-Amarelo e Latossolo VermelhoAmarelo argissólico (LV2), Latossolo VermelhoAmarelo (LV1)Latossolo Amarelo com inclusões de solos do tipo Latossolo Vermelho-Amarelo (LA) e na parte sudoeste, área onde está localizada a cidade de Açailândia, tem-se a associação de solos P (Argissolo Vermelho-Amarelo, Argissolo Vermelho-Amarelo latossólico, Argissolo Amarelo, Argissolo Amarelo latossólico). O relevo é do tipo suave ondulado a ondulado, correspondendo às áreas com o índice de desmatamento mais elevado e com atividades de ocupação mais intensa, quando comparados com os setores descritos. A erosão em voçoroca é mais freqüente, ocorrendo também em forma de ravinas (Marçal, 2000).

3.2 - Transformação do uso da terra nos anos de 1985, 1991 e 1996 e a ocorrência de processos erosivos

As informações sobre áreas desmatadas no município de Açailândia, desde seu surgimento na década de 60 até o fim dos anos 80 , revelaram que as causas tradicionais de desmatamento estiveram ligadas à construção de rodovias, à exploração madeireira, à abertura de roças e à formação de pastagens. As queimadas periódicas sazonais usadas para limpeza 
das pastagens, com vistas à eliminação de plantas indesejáveis e as ocorrências de fogo acidental são responsáveis pela queima de grandes áreas.

Com base na análise e avaliação dos mapeamentos digitais referentes ao uso da terra, pode-se verificar que a distribuição e a freqüência das classes ao longo de toda a área, sofreu um intenso processo de transformação (Figura 2). No mapa apresentado, se considera como setor agropastoril toda a atividade pertinente à retirada da vegetação para pasto $\mathrm{e}$ agricultura, estejam elas com ou sem vegetação. Estão também incluídas nesta classe, as atividades exercidas pela construção de rodovias e ferrovias, a exploração madeireira, as aberturas de roça e a implantação da indústria madeireira; os setores núcleo urbano e área industrial são analisados separadamente, com intenção de visualizar sua expansão dentro do período estudado, ainda porque, esta última só veio existir a partir de 1989. No setor vegetação, inclui-se tanto a floresta nativa como áreas com vegetação secundária, mas que não apresentam atividade antrópica.

Analisando o mapa de 1985 (Figura 2),

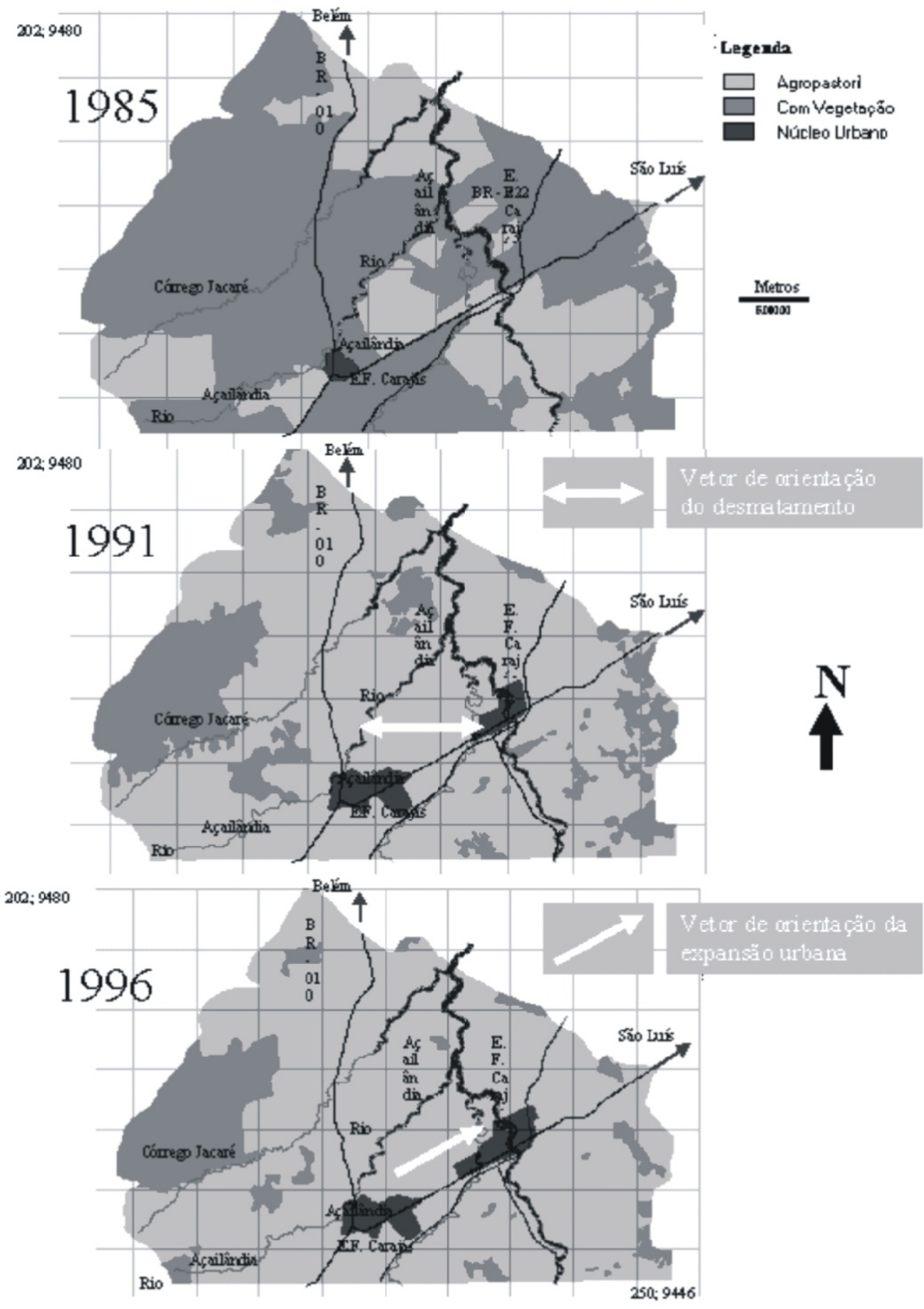

Figura 2- Transformação do Uso do Solo no Alto Curso da Bacia do Rio Açailândia 
observa-se que extensas áreas com vegetação predominavam em relação ao setor agropastoril e, comparando-se com os anos subsequentes, é notória a expansão da atividade antrópica. O núcleo urbano, nesse ano, estava em processo de crescimento e expansão, visto que a cidade de Açailândia tinha passado a ser sede do então município, em 1981. Até este período o desmatamento das florestas nativas foi relativamente baixo, principalmente nas áreas cortadas pela Estrada de Ferro Carajás. A retirada da vegetação concentrava-se, principalmente, nas áreas próximas ao rio Açailândia, ao córrego Pequiá, e ao longo da BR-222.

No mapeamento de 1991, observa-se o aumento considerável do setor agropastoril. Com base em análise de geoprocessamento é possível se inferir vetores de orientação da expansão ou retração das classes de uso do solo. No caso da área estudada, a expansão orienta sua projeção para as áreas com vegetação identificadas no ano de 1985 , caracterizadas pelas porções mais baixas e planas da bacia, deixando grande parte das áreas com vegetação nas partes mais elevadas, correspondente àquelas situadas próximo aos limites leste-oeste da bacia. Por conseguinte, as áreas com vegetação foram muito reduzidas em área, sendo que a menor redução foi na parte oeste (Figura 2). Neste período, o desmatamento é também motivado pelas guserias consumidoras de carvão vegetal, que se instalavam em Açailândia desde 1988.

Dessa forma, o rápido avanço das áreas desmatadas para atividades agropastoris até o ano de 1991 deve-se, sobretudo, à contínua prática de queimadas, criação de gado, expansão urbana, exploração madeireira sem técnicas adequadas e a implantação de indústrias madeireiras e siderúrgicas (guserias). Neste período, a nova Estrada de Ferro Norte-Sul percorre parte do município, encontrandose com a ferrovia de Carajás em Pequiá, na estação de Açailândia, estimulando a Prefeitura e o Governo do Estado a criarem o Distrito Industrial em Pequiá.Com relação ao setor urbano, este sofreu considerável expansão, principalmente no eixo da rodovia BR-222, em direção ao então criado Distrito Industrial de Pequiá e acompanhando o entorno da Estrada de Ferro Carajás.

No mapeamento de 1996 (Figura 2), é evidente grande redução das áreas com vegetação em relação ao predomínio das áreas com atividades antrópicas (agropastoril). As poucas manchas de vegetação concentram-se ainda nas partes mais elevadas. A expansão considerável da classe agropastoril se deve principalmente ao intenso processo de desmatamento para atividade agropecuária e da indústria madeireira e siderúrgica. Aexpansão do setor urbano direciona-se sobre o eixo da rodovia BR-222 e para as áreas localizadas ao sul da cidade, em direção à Estrada de Ferro Norte-Sul. O distrito industrial também apresenta expansão em área principalmente em direção à cidade. Vale ressaltar, contudo, que
Açailândia em 1985, encontrava-se ainda cercada pelas áreas com vegetação, ao contrário do que se pode observar nos anos de 1991 e 1996.

A Tabela 1 mostra os valores da distribuição em área dos setores de uso registrados no mapeamento. A área total abrange $1.009 \mathrm{Km}^{2}$ e os valores de perda e da expansão dos setores agropastoril, área com vegetação, núcleo urbano e área industrial foram calculadas a partir da subtração dos valores de 1985 e 1996 e apresentados em percentual. Da mesma forma, as classes em que se verificou expansão de área, foram calculadas a partir da subtração dos valores de 1996 e 1985 e apresentados em percentual (Tabela 2).

A partir da observação do mapa apresentado na Figura 2, e com base nos trabalhos de campo e os realizados sobre a elaboração do mapa de declividade das vertentes como ferramenta para o estudo dos voçorocamento, no núcleo urbano, em áreas de pastagem e ao longo das rodovias e ferrovias, favorecidos pela retirada da cobertura vegetal. São portanto, os setores mais propícios à ocupação humana em relação ao setor de declividade maior (8$20 \%$ ). Por outro lado, nas áreas onde a declividade aumenta e impõe difícil acesso ao homem, a ocorrência erosiva diminui, principalmente, em função da preservação da vegetação (Garcia et al., 1998; Marçal, 2000).

\section{Relações entre os fatores ambientais e os processos erosivos}

Os solos no alto curso da bacia do rio Açailândia apresentam propriedades físico- químicas que os tornam de maior suscetibilidade à erosão, sendo o relevo compartimentado em níveis de dissecação com declividades que variam de plana a forte ondulada.

A litologia, predominantemente sedimentar, corresponde à área pouco compactada e arenosa que pode apresentar, em algumas partes da bacia, estruturas resultantes de deformações regionais, favorecendo a ação de processos erosivos, e com isso delimitando os setores potencias a sua ocorrência (Marçal, 2000). Associa-se ainda, a intensa precipitação concentrada durante três meses do ano (janeiro, fevereiro e março). Todos esses são fatores que, em conjunto com a estrutura sócio-econômica do município (estabelecimento de madeireiras, guserias e siderúrgicas), explicam o surgimento e intensificam o desenvolvimento dos processos erosivos.

As análises granulométricas apresentam-se como um dos fatores determinantes na erodibilidade dos solos, junto com o teor de matéria orgânica. Os estudos mostraram que as areias finas, em geral, predominam em relação à areia grossa. A associação dos solos LVA1 (Latossolo Vermelho-Amarelo) e LVA2 (Latossolo Vermelho-Amarelo e Latossolo Vermelho-Amarelo argissólico) e dos solos LA 
Tabela 1 - Valores obtidos das classes de uso registradas para o alto curso da bacia do rio Açailândia

\begin{tabular}{|c|c|c|c|c|c|c|}
\hline \multirow{2}{*}{$\begin{array}{c}\text { Classes de Uso } \\
\text { Registradas } \\
\text { T }\end{array}$} & \multicolumn{2}{|c|}{1985} & \multicolumn{2}{|c|}{1991} & \multicolumn{2}{|c|}{1996} \\
\hline & $\mathrm{Km}^{2}$ & $\%$ & $\mathbf{k m}^{2}$ & $\%$ & $\mathbf{k m}^{2}$ & $\%$ \\
\hline Agropastoril & 321,40 & 31,84 & 790,84 & 78,38 & 840,10 & 83,26 \\
\hline Com Vegetação & 683,15 & 67,70 & 192,45 & 19,07 & 136,61 & 13,55 \\
\hline Núcleo Urbano & 4,35 & 0,46 & - & - & - & - \\
\hline $\begin{array}{l}\text { Núcleo Urbano e } \\
\text { Área Industrial }\end{array}$ & - & - & 25,63 & 2,55 & 32,19 & 3,19 \\
\hline
\end{tabular}

Tabela 2 - Valores em porcentagem das perdas e expansão das classes encontradas no período de 11 anos (1985 - 1996).

\begin{tabular}{|c|c|c|c|c|}
\hline \multirow{2}{*}{ Classe de uso } & \multicolumn{2}{|c|}{ Área Total (Km) ${ }^{2}$} & Perda & Expansão \\
& $\mathbf{1 9 8 5}$ & $\mathbf{1 9 9 6}$ & $\%$ & $\%$ \\
\hline $\begin{array}{c}\text { Área } \\
\text { Agropastoril }\end{array}$ & 321,4 & 840,1 & - & 51,42 \\
\hline $\begin{array}{c}\text { Área com } \\
\text { vegetação }\end{array}$ & 683,1 & 136,6 & 54,15 & - \\
\hline $\begin{array}{c}\text { Núcleo urbano }+ \\
\text { Área industrial }\end{array}$ & - & - & - & 2,76 \\
\hline
\end{tabular}

(Latossolo Amarelo com inclusões de Latossolo Vermelho-Amarelo) apresenta-se com textura mais arenosa em relação aos solos da associação $\mathbf{P}$ (Argissolo Vermelho-Amarelo, Argissolo Amarelo, Argissolo Vermelho-Amarelo latossólico e Argissolo Amarelo latossólico) que mostram textura com mais argila.

Entretanto, as amostras de solos coletadas no talude das voçorocas (área urbana e rural) mostram o predomínio da fração areia grossa em relação à fração areia fina. Este fato leva a acreditar que a areia fina tenha sido transportada por fluxos de água concentrada através de processos erosivos nas encostas. Conforme o mapeamento e monitoramento realizados em áreas de voçoroca, pode-se observar a presença constante de um cone deposicional na sua base, constituído basicamente de areia muito fina (Marçal, 2000).

Com isso, pode-se apontar que os solos de textura predominantemente arenosa, em conformidade com o baixo teor de matéria orgânica, correspondem aos elementos mais ativos na falta de agregabilidade das partículas do solo. Tal situação se agrava, nos períodos onde os índices pluviométricos são concentrados, entre os meses de dezembro a maio, cujos valores de precipitação são bem mais elevados em relação aos outros meses do ano (Marçal et al., no Prelo). 
Os gráficos da Figura 3 mostram a relação entre os teores de areia fina, areia grossa, silte e argila em Latossolo Vermelho-Amarelo e Argissolo Vermelho-Amarelo, representativos da área rural do alto curso da bacia do rio Açailândia. Como se pode observar, o teor de areia (fina e grossa) predomina no Latossolo Vermelho-Amarelo, enquanto que os valores de argila aparecem como predominantes no Argissolo Vermelho-Amarelo, apesar da areia (fina e grossa) possuir teores também elevados.
(A) ANÁLISE GRANULOMÉTRICA EM LATOSSOLO VERMELHO-AMARELO

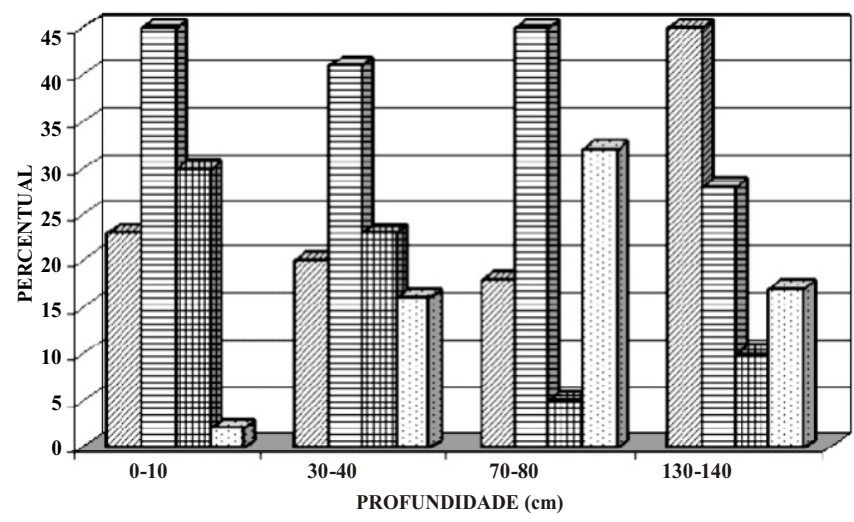

(B) ANÁLISE GRANULOMÉTRICA EM LATOSSOLO AMARELO

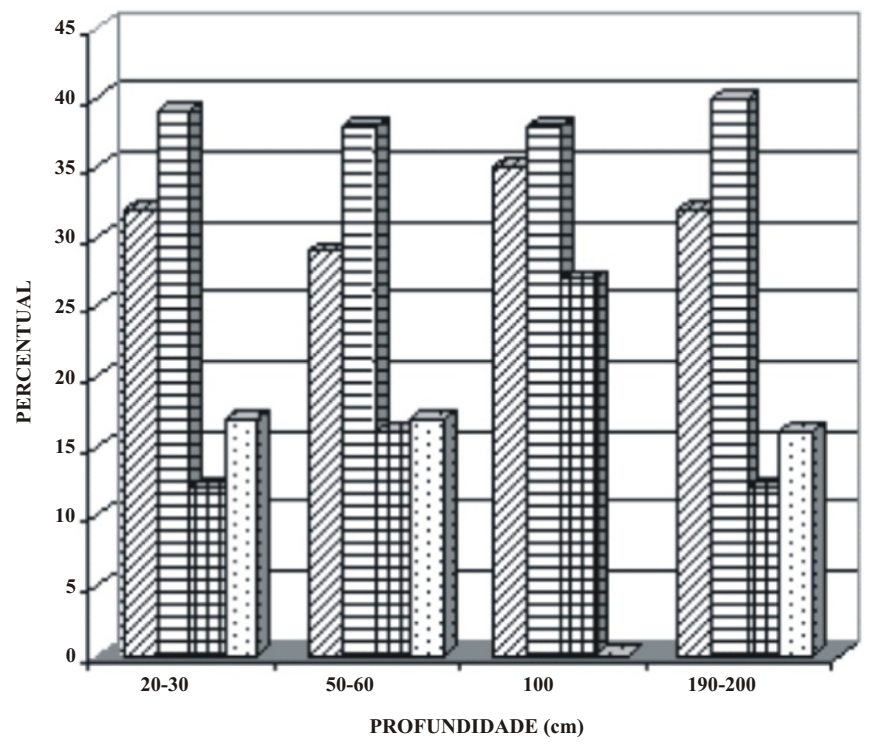

(C) ANÁLISE GRANULOMÉTRICA EM ARGISSOLO VERMELHO - AMARELO

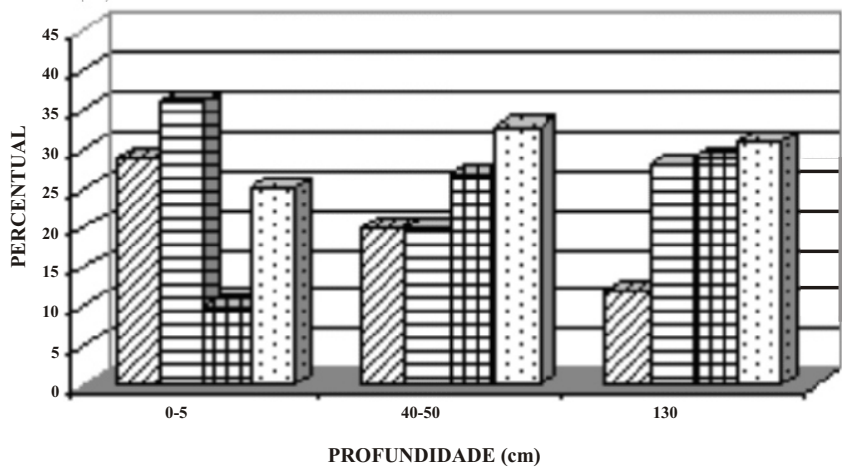

๑ Areia Grossa

日 Areia Fina

田 Silte

$\square$ Argila

\section{चreia Grossa \\ 日 Areia Fina \\ 团 Silte \\ $\square$ Argila}

$\square$ Areia Grossa
$\square$ Areia Fina
团 Silte
$\square$ Argila

Figura 3 - Teores de areias grossa e fina, silte e argila na área rural de Açailândia em: (A) Latossolo VermelhoAmarelo; (B) Latossolo Amarelo e (C)Argissolo Vermelho-Amarelo. 
Observa-se ainda, que há predominância da areia fina sobre a grossa em ambos os solos. Situação contrária ocorre nas amostras de solos coletadas dentro das voçorocas, como mostra o gráfico da Figura 4 (Marçal, 2000).

Localizada em área de relevo dissecado, distribuídos em três níveis topográficos distintos e inclinados em direção ao centro da bacia, observa-se que a Através dos trabalhos de mapeamento, em conformidade com os dados de campo, pode-se observar que nos setores onde a declividade do terreno é menor ( 0 a $8 \%$ ), está ocorrendo o maior índice de desmatamento e, por sua vez, aparece o maior número de feições erosivas. São setores considerados, sob o ponto de vista topográfico, mais propícios às atividades de ocupação humana, em relação aos setores de maior declividade degradação por erosão vem ocorrendo com maior intensidade nas áreas mais baixas (correspondendo ao médio/baixo curso dos rios), onde se verifica que a atividade antrópica é mais intensa do terreno ( 8 a $20 \%$ ).

Coincidentemente, nas áreas dos setores de menor declividade, ocorre o predomínio dos solos com textura arenosa e, por sua vez, nos setores cuja declividade encontra-se mais elevada ( 8 a $20 \%$ ), ocorrem, dominantemente, os solos com textura mais argilosa a média, não sendo, contudo, predominante na área (Garcia et.al., 1998; Marçal, 2000).

Nas áreas de ocorrência da associação de Latossolo e intergrade com Argissolos, há uma tendência à ocorrência de processos erosivos, em relação à associação de solos tipo Argissolo e intergrade com Latossolo. Tal fato demonstra, que as feições erosivas não estão, necessariamente, relacionadas com áreas de declive mais elevadas, como tradicionalmente descrito, e sim, que outras variáveis combinadas entre si estão influenciando no processo de erosão na região, ressaltando-se e reforçando-se a idéia de que a textura e o uso da terra, podem ser os fatores preponderantes nesses processos de erosão.

Os altos teores de areia (que variam de $40 \mathrm{a}$ $80 \%$, sendo $64 \%$ o valor médio) e baixos de argila, nos solos identificados, bem como os baixos teores de matéria orgânica (variam entre $0,95 \%$ a 3,48\%), vêm contribuindo para a alta suscetibilidade à erosão em várias partes do alto curso da bacia do rio Açailândia (Marçal, 2000).

Apesar da topografia relativamente plana da bacia, seus solos não estão livres do risco de erosão. Ao contrário, o índice de desmatamento e os resultados das análises dos solos serviram para evidenciar a alta erodibilidade desses solos, face às características ambientais gerais da área.

Segundo Guerra (1998 e 1999), a erosão dos solos no Brasil está associada às propriedades dos solos e às condições climáticas. Esses fatores quando associados com desmatamento, uso agrícola da terra e às queimadas intensificam e aceleram a ação do processo erosivo. Essa combinação de fatores físicos e sócio-econômicos, quase sempre leva à ocorrência de processos erosivos acelerados.

Para o alto curso da bacia do rio Açailândia, o rápido crescimento urbano, associado à industrialização, ao desmatamento, às queimadas, às condições pedológicas, geomorfológicas, geológicas e climáticas, têm sido responsáveis pelo aumento da ação erosiva dos solos, propiciando um quadro de significativa degradação. Enquanto na década de 70, a população do então povoado de Açailândia era de 2.107 habitantes, em 1981, quando o município foi criado, já era de 52.455 habitantes e, em 1996, segundo dados do Instituto Brasileiro de Geografia e Estatística (IBGE), já atingiam 102.609 pessoas, ou seja, sua população total duplicou, em um período de apenas 20 anos.

\section{Identificação das Áreas Suscetíveis à Erosão}

Os cruzamentos, ou integração dos dados, envolveram as informações básicas de relevo, solo e uso, visando a produção de um mapa que hierarquizasse as áreas de risco a ocorrência de erosão. Foram plotados pontos mapeados de feições erosivas lineares típicas da região, caracterizadas por voçorocas e ravinamentos.

Destaca-se, que apesar da literatura geomorfológica (Oliveira et.al., 1992; Guerra \& Botelho, 1998) apontar os maiores riscos de erosão para os Argissolos e os menores riscos para os Latossolos, na área estudada aconteceu justamente o contrário. Os solos foram agrupados em dois grandes grupos com base na granulometria, especificamente areias e argilas, uma vez que estas frações respondem diretamente sobre o comportamento erosivo do solo. Assim, considerou-se que os Latossolos, por possuírem uma fração granulométrica mais arenosa, representam os tipos de solo mais erodíveis. Por outro lado, o grupo dos Argissolos foi considerado menos suscetível por demonstrar uma fração granulométrica mais argilosa.

Quanto à geomorfologia, considerou-se que há uma faixa entre as fácies de dissecação que são mais suscetíveis à ação erosiva, devido à transição morfológica do relevo. Entretanto, esta faixa não pode ser representada devido ao tipo de mapeamento em escala regional. Ressalta-se, ainda que as fácies mais rebaixadas (F2 e F3) comportam-se como zonas preferenciais de ocorrência de processos erosivos, em relação à fácie $\mathrm{F} 1 \mathrm{e}$ a superfície de aplainamento $\mathrm{Pd} 3$ que se encontram mais preservadas, em termos de uso e ocorrência de processos erosivos (Marçal, 2000).

A presença da vegetação de grande e médio porte torna-se relevante na ocorrência, ou não, dos processos erosivos. A floresta proporciona, em grande parte, a formação de húmus, importante para a estabilidade dos agregados, protegendo o solo da ação do escoamento superficial, e as condições de 
(A) ANÁLISE GRANULOMÉTRICA NA VOÇOROCA DO JACU

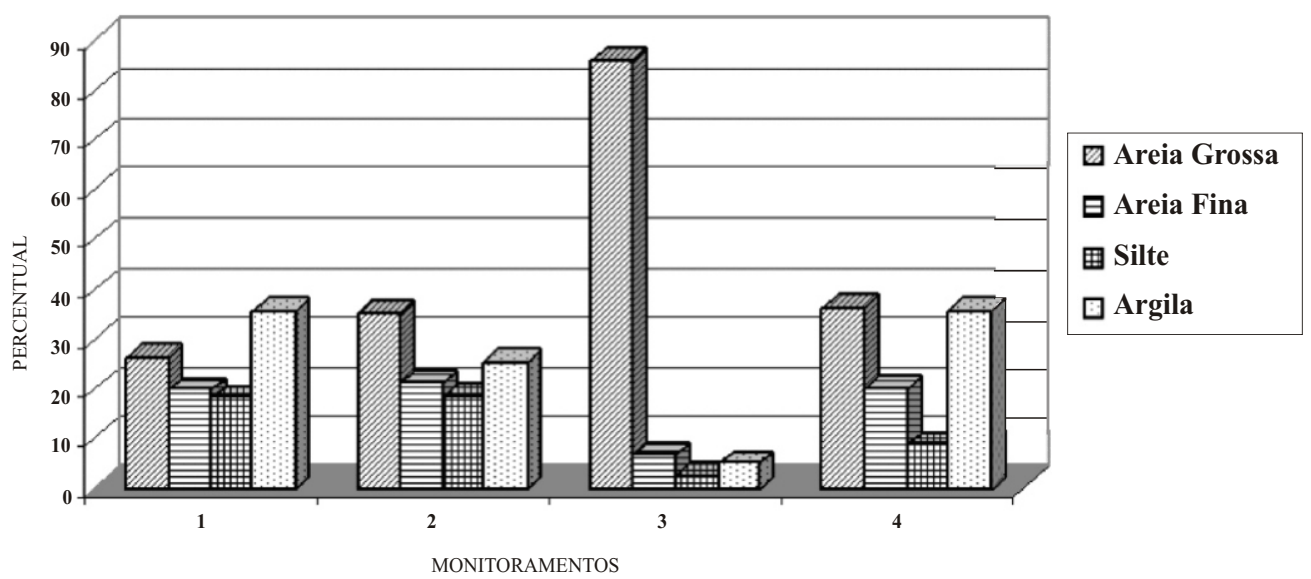

(B) ANÁLISE GRANULOMÉTRICA NA VOÇOROCA DO EUCALIPTO

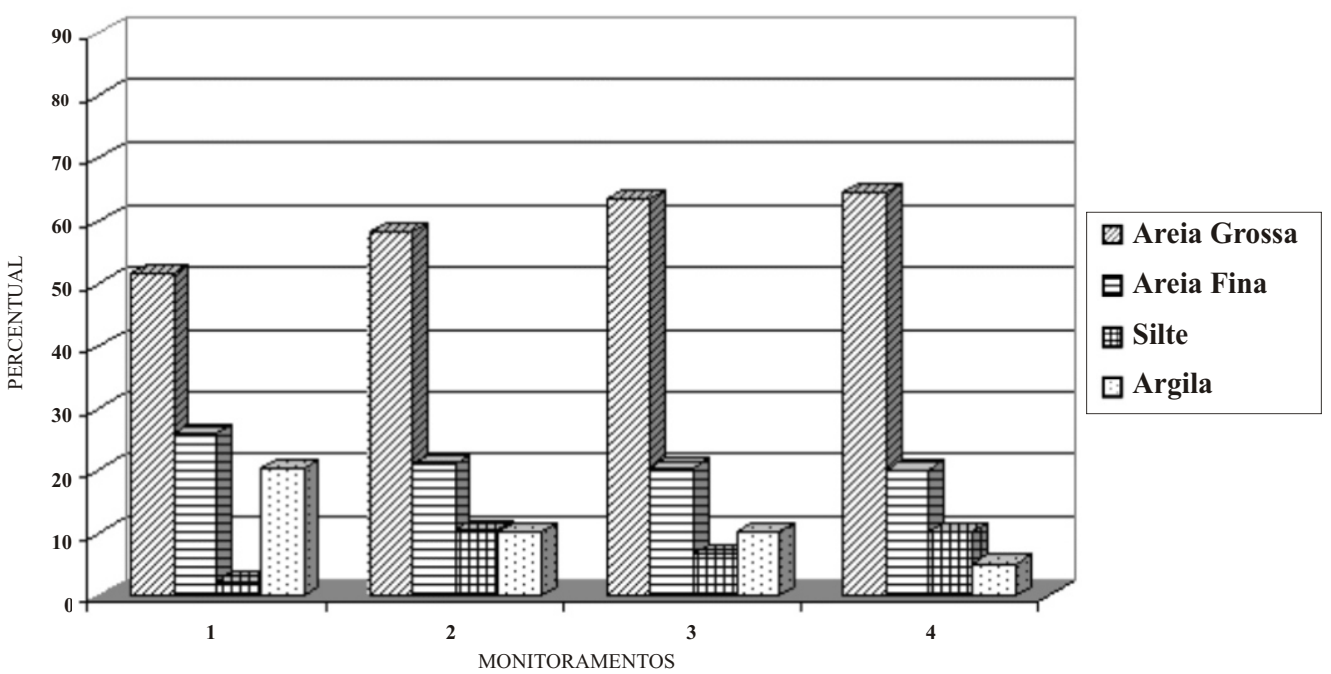

(C) ANÁLISE GRANULOMÉTRICA NA VOÇOROCA VÉU-DE-NOIVA

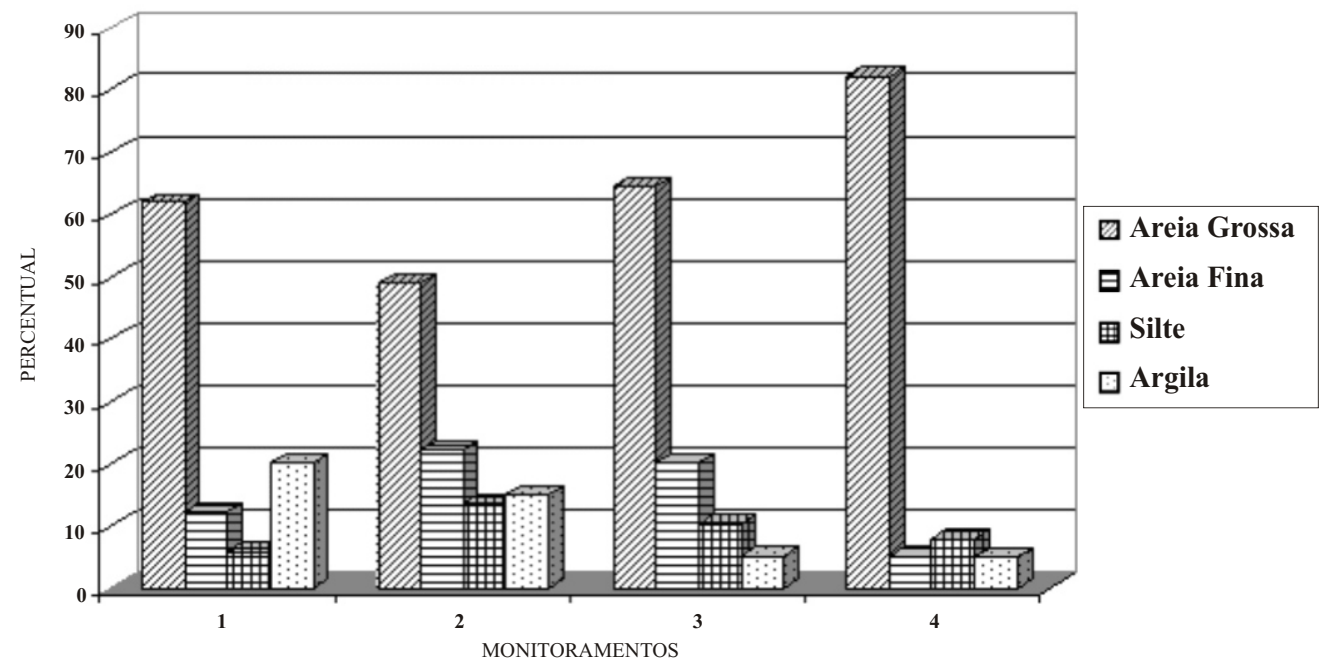

Figura 4. Teores de areias grossa e fina, silte e argila em pontos dos taludes de três voçorocas monitoradas na área urbana: (A) Voçoroca do Jacu; (B) Voçoroca do Eucalipto e (C) Voçoroca Véu-de-Noiva (Marçal, 2000). 
infiltração também são maiores. Nas áreas não florestadas (agropastoril), o solo está mais exposto à ação dos processos erosivos, onde nos períodos mais chuvosos estabelece-se com mais intensidade, o aumento nas taxas de escoamento superficial, que são, em grande parte, responsáveis pela perda do solo na área (Marçal, 2000).

A partir do cruzamento entre os três fatores ambientais (solo, relevo e uso) e feições erosivas, foram obtidas as seguintes classes (Figura 5):

$\S \quad$ (uso) Agropastoril x (solo) Argissolos $x$ (relevo) F1 x F2 x F3 Este compartimento mostra-se menos afetado por processos erosivos lineares. No entanto, destaca-se que nestas áreas as mudanças de relevo entre fácies de dissecação denotam uma fragilidade nas faixas de transição, principalmente por estarem sem vegetação nativa;

$\S \quad$ (uso) Agropastoril $x$ (solo) Latossolos $x$ (relevo) F2 x F3 - A combinação desses fatores demonstram que estas áreas são sensíveis sob o ponto de vista do tipo de solo, considerando-se as relações granulométricas, e fácies de dissecação. Porém, potencializam-se pela atividade antrópica, onde a retirada da vegetação acelerou a ocorrência de processos erosivos;

$\S \quad$ (uso) Agropastoril x (solo) Latossolos $x$ (relevo) Pd3 Apesar da combinação dos fatores tipo de solo e tipo de uso apontarem para áreas consideradas sensíveis à ocorrência de processos erosivos, sob o ponto de vista geomorfológico, elas se tornam áreas mais estáveis, pois se localizam em terrenos elevados, porém planos;

$\S \quad$ (uso) Florestas $x$ (solo) Argissolos $x$ (relevo) F1 x F2 x F3 Este compartimento encontra-se praticamente não afetado por processos erosivos. No entanto, com base na observação da dinâmica dos processos erosivos na região, destaca se o fator vegetação como principal elemento de contenção da erosão;

$\S \quad$ (uso) Urbano x (solo) Argissolos x (relevo) F2 x F3 São áreas que se apresentam sob o ponto de vista granulométrico mais estáveis (mais argiloso), porém, a combinação dos outros fatores denota a alta suscetibilidade à ocorrência da erosão, o que neste caso, principalmente associa-se à ação antrópica (núcleo urbano);

$\S$ (uso) Florestas $x$ (solo) Latossolos $x$ (relevo) Pd3 Apesar da combinação dos fatores físicos, uso da terra e geomorfologia apontarem como pouco suscetíveis à erosão, neste caso, o fator solo, que é mais arenoso, destaca-se na suscetibilidade à ocorrência de erosão na área;

$\S \quad$ (uso) Urbano x (solo) Argissolos x (relevo) F2 x F3 São áreas que se apresentam sob o ponto de vista granulométrico mais estáveis (mais argiloso), porém, a combinação dos outros fatores denota a alta suscetibilidade à ocorrência da erosão, o que neste caso, principalmente associa-se à ação antrópica (núcleo urbano);

$\S \quad$ (uso) Urbano x (solo) Latossolo $x$ (relevo) F2 x F3 Esta classe se caracteriza por congregar a combinação dos três fatores ambientais à ocorrência de processos erosivos, sendo portanto, considerada crítica à ocorrência de erosão.

A análise do cruzamento entre os fatores solo, relevo e uso da terra levou à produção do Mapa Síntese (Figura 6), elaborado a partir da reclassificação (agrupamento de classes afins). Nesta reclassificação foram consideradas todas as informações relacionadas à erosão, delimitando-se e hierarquizando-se novas áreas, de acordo com a suscetibilidade ao desencadeamento destes processos.

Uma vez que o presente trabalho trata da análise de fatores ambientais regionais, um mapa síntese corre o grande risco de fugir à realidade, não traduzindo de fato, as condições locais de suscetibilidade. Entretanto, neste caso, este mapa demonstra que a ocorrência da erosão não se associa a um único fator ambiental isolado, mas à combinação de fatores que levam a uma maior ou menor suscetibilidade, na área de estudo. Reagrupando as classes do mapa anterior foram geradas três classes de síntese visando-se à explicação da ocorrência do processo erosivo em Açailândia.

A classe 1 (Pouco Suscetível) corresponde ao seguinte agrupamento:

Quanto ao tipo de uso é Agropastoril e Florestas; quanto ao relevo, fácies de dissecação F2, F3 e Pd3 ; quanto aos solos, associação de Latossolos.

A classe 2 (Suscetível) corresponde ao seguinte agrupamento:

Quanto ao tipo de uso é Agropastoril; quanto aos solos associação de Latossolos e Argissolos; quanto ao relevo, fácies de dissecação F1, F2 e F3.

A classe 3 (Crítica) corresponde ao seguinte agrupamento:

Quanto ao tipo de uso é Urbano; quanto aos solos associação de Latossolos e Argissolos; quanto ao relevo fácies de dissecação F2 e F3.

Conforme já exposto, esta síntese delimita de forma genérica os domínios hierarquizados da suscetibilidade à erosão. Destaca-se a área urbana como crítica, devido ao forte controle exercido pela 


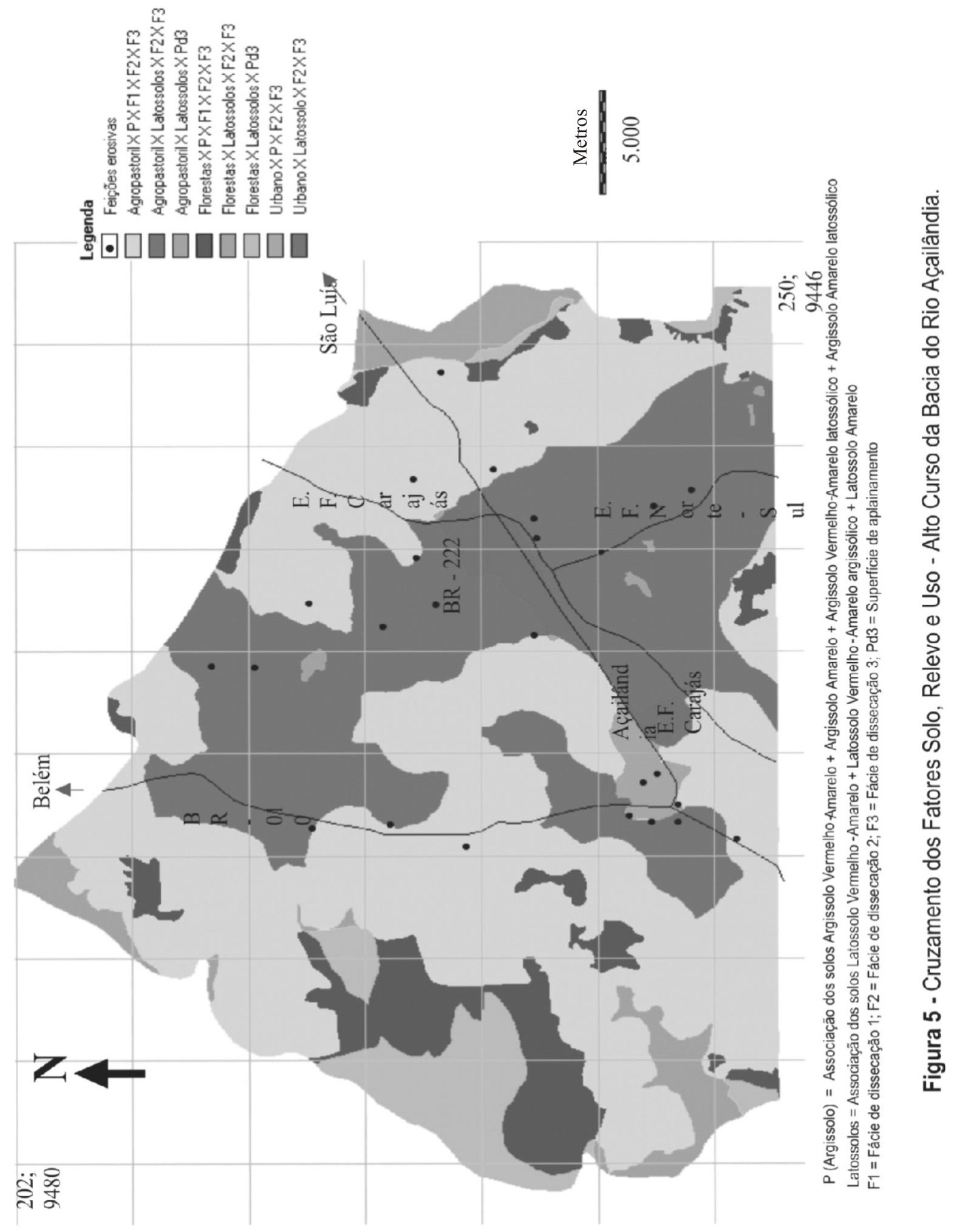



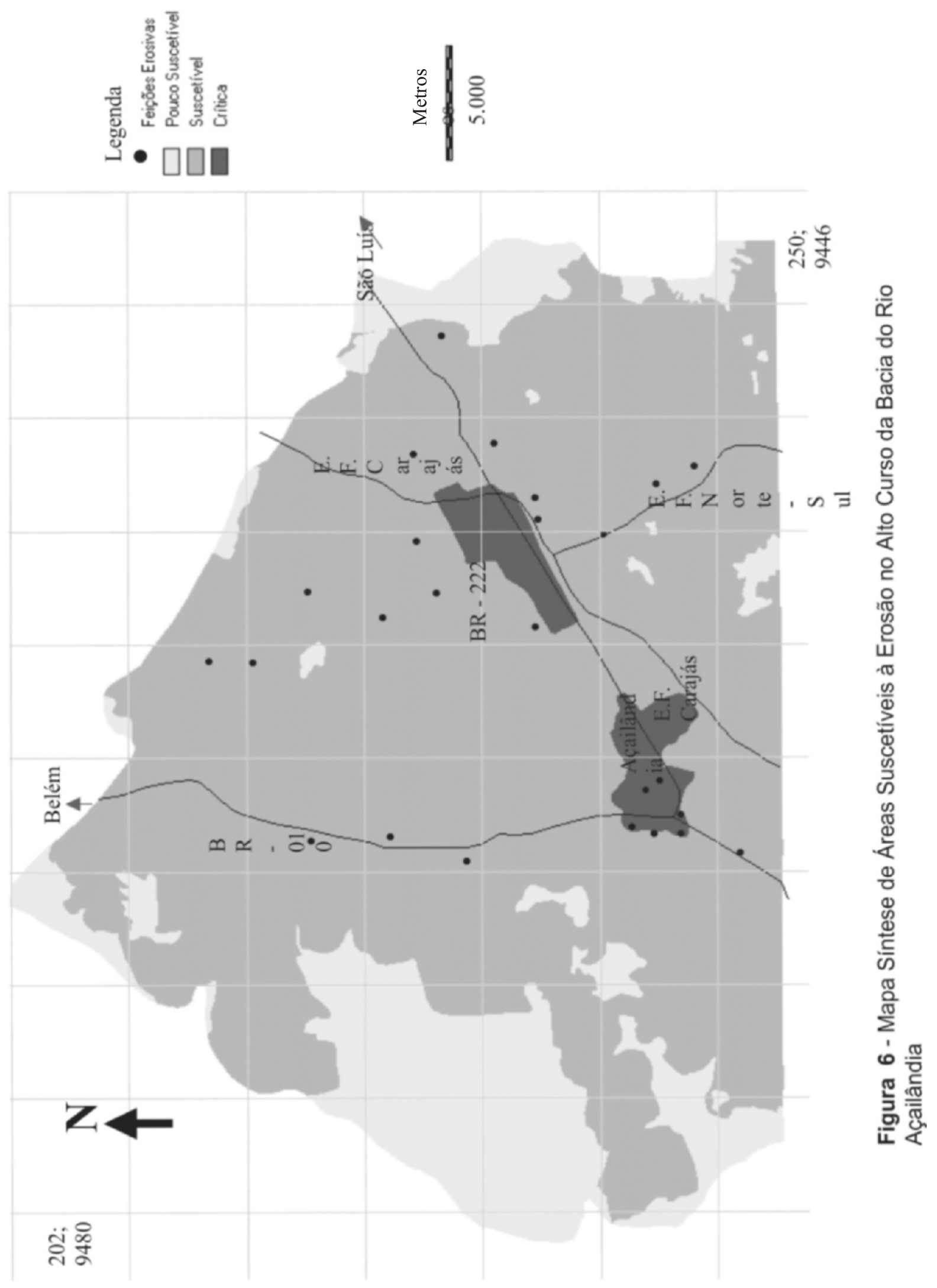
atividade humana na geração e potencialização de antigos e novos processos erosivos. As classes suscetível e pouco suscetível associam-se, preferencialmente, à combinação dos fatores físicos, que da mesma forma como na classe crítica à ação humana torna-se efeito decisivo na ocorrência destes processos.

As análises do cruzamento entre os fatores ambientais solo, relevo e uso da terra com o mapa de ocorrência dos processos erosivos, demonstra que a incidência da erosão em nível regional pode estar associada às descontinuidades do relevo, sendo potencializadas pela intervenção humana.

\section{Conclusões}

O presente trabalho evidencia como o estudo dos processos erosivos é altamente complexo e depende de uma série de variáveis para a sua compreensão. Nesse estudo levou-se em consideração o relevo, as classes de solo, o uso da terra e a cobertura vegetal.

Esses fatores apresentam respostas diferenciadas na ocorrência dos processos erosivos. $\mathrm{O}$ solo tem um importante papel na ocorrência da erosão. Assim como os demais fatores, se tomado de forma isolada não responde à questão do problema.

Este se comporta dominantemente arenoso, sendo que na escala local apresenta individualizações com relação à sua composição granulométrica, que lhe confere diferentes potencialidades à erosão. Como demonstrado, as feições erosivas são freqüentes nos setores onde ocorre a predominância dos solos mais arenosos, que no caso, correspondem à associação dos Latossolos.

Nas áreas de ocorrência da associação dos Argissolos, que texturalmente são mais argilosos, temse o registro de ocorrência de erosão, menor do que na área da associação dos Latossolos.

Estas condições, quando analisadas juntamente com o clima da região de fortes chuvas concentradas no verão e o tipo de uso da terra, caracterizado por intenso desmatamento para atividades agropastoris, alcançam delimitações e restrições impostas pelos elementos que estão influenciando na fragilidade do terreno, respondendo de forma diferenciada à questão da erosão como pode ser observado no Mapa da Figura 5. Aliam-se a esse quadro, os problemas sociais em Açailândia decorrentes, em grande parte, do processo e da forma de ocupação que se deu o município, que não podem ser vistos dissociados ou alheios de um contexto histórico no qual se insere. Combinada a esses fatores, há uma tendência das feições erosivas ocorrerem preferencialmente próximo às zonas de transição entre fácies de dissecação do relevo.

Todos esses aspectos analisados conjuntamente, retratam bem o papel do uso da terra como um fator importante na geração dos processos erosivos e mudanças na paisagem da bacia do rio Açailândia. 